\title{
Application of a Novel Metallomics Tool to Probe the Fate of Metal-Based Anticancer Drugs in Blood Plasma: potential, challenges and prospects
}

\author{
Sophia Sarpong-Kumankomah, ${ }^{\mathrm{a}}$ and Jürgen Gailer ${ }^{\mathrm{a}^{*}}$ \\ ${ }^{a}$ Department of Chemistry, Faculty of Science, University of Calgary, Calgary, Canada
}

\begin{abstract}
Although metallodrugs are in use to treat a variety of human disorders and exhibit a remarkable diversity of therapeutic properties, they constitute only a tiny minority of all medicinal drugs that are currently on the market. This undesirable situation must be partially attributed to our general lack of understanding the fate of metallodrugs in the extremely ligand-rich environment of the bloodstream. The challenge of gaining insight into these bioinorganic processes can be overcome by the application of 'metallomics tools', which involve the analysis of a biological fluid (e.g. blood plasma) with a separation method in conjunction with multi-element specific detectors. To this end, we have developed a metallomics tool that is based on size-exclusion chromatography (SEC) hyphenated to an inductively coupled plasma atomic emission spectrometer (ICP-AES). After the successful application of SEC-ICP-AES to analyze plasma for endogenous copper, iron and zinc-metalloproteins, it was subsequently applied to probe the metabolism of a variety of metal-based anticancer drugs in plasma. The versatility of this metallomics tool is exemplified by the fact that it has provided insight into the metabolism of individual Pt-based drugs, the modulation of the metabolism of cisplatin by sulfur-containing compounds, the metabolism of two metal-based drugs that contain different metals as well as a bimetallic anticancer drug, which contained two different metals. After adding pharmacologically relevant doses of metallodrugs to plasma, the temporal analysis of aliquots by SECICP-AES allows to observe metal-protein adducts, metallodrug-derived degradation products and the parent metallodrug(s). This unique capability allows to obtain comprehensive insight into the fate of metal-based drugs in plasma and can be extended to in vivo studies. Thus, the application of this metallomics tool to probe the fate of novel metal-complexes in plasma that exert the desired biological activity has the potential to advance more metal-based drugs to animal/preclinical studies to fully explore the potential that metallodrugs inherently offer.
\end{abstract}

Keywords: metal-based drugs, combination therapy, bimetallic complexes, biotransformation, safety, side-effects, metallomics, drug development.

\section{INTRODUCTION}

Despite considerable advances in the early diagnosis ${ }^{1}$ and the treatment of cancer ${ }^{2}$, this disease remains a considerable burden to the world economy. ${ }^{3-4}$ Accordingly, considerable research efforts continue to be directed to improve this undesirable situation ${ }^{5}$. While remarkable clinical success has been recently achieved with monoclonal antibodies, antibodydrug conjugates ${ }^{6}$ and immunomodulatory agents ${ }^{7}$, bioinorganic chemists contribute by developing metallodrugs that exert better tumor selectivity ${ }^{8-9}$ and investigate drug delivery vehicles which can more selectively deliver metallodrugs to the tumor to minimize off-target effects ${ }^{8,10-}$ 12. Another strategic approach aims to improve the safety of established metallodrugs by systematically mitigating their often severe side effects ${ }^{13}$ based on deliberately modulating their metabolism in blood plasma by the adventitious intravenous co-administration of chemoprotective agents ${ }^{14-15}$. Despite considerable research efforts over the past 30 years, however, metal-based drugs still represent only a tiny fraction of all medicinal drugs that are currently on the market ${ }^{16}$.
Those metallodrugs that are approved by a regulatory body (e.g. FDA), do exhibit a remarkable diversity of therapeutic properties as they are in use as anticancer drugs, photochemotherapeutic drugs, antimicrobial/antiparasitic drugs, antiarthritic drugs, antidiabetic drugs, antiviral drugs, drugs for the treatment of cardiovascular disorders, gastrointestinal disorders and psychotropics ${ }^{5}$.

\footnotetext{
*Address correspondence to this author at the Department of Chemistry, Faculty of Science, University of Calgary, 2500 University Drive NW, Calgary, AB, T2N 1N4, Canada. Tel/Fax: ++1-403-210-8899, +1-403-2899488; E-mails: jgailer@ucalgary.ca

This observation combined with the fact that a six-coordinate metal center offers inherently more geometric possibilities to tailor the desired biological activity of a lead drug ${ }^{9}$ compared to a carbon-system with a maximum coordination number of four ${ }^{16}$ underscore the inherent potential that metallodrugs offer for future drug development. Metal-based drugs also have the potential to target several sites (multi-targeting), which can be a highly effective strategy ${ }^{9}$. While a brief glance at the recent scientific literature reveals an apparent upsurge in the discovery of novel metal-based drug candidates which
} 
offer the desired biological activity ${ }^{17}$, it is perhaps surprising that comparatively few enter clinical studies. This somewhat puzzling fact must be largely attributed to the practical difficulty that is associated with determining to what extent a novel metalloentity that is introduced into the bloodstream fulfills the required features of an ideal prodrug ${ }^{18}$ :

- it should be stable and non-toxic in the bloodstream

- it should exhibit minimal uptake by red blood cells and other non-target cells

- it should be rapidly uptaken and activated by tumor cells to reach a concentration that kills the cell

- the active agent should be able to reach the regions of the cell (e.g. sub-cellular compartment) where the toxic action ensues (e.g. binding to the DNA).

In this context, the inability of a novel metallodrug that exhibits the desired biological activity (e.g. its $\mathrm{IC}_{50}$ value in a relevant cell type is comparable to that of cisplatin) to reach all target cells in concentrations that are sufficient to exert the desired effect is believed to be the major course of their frequent failure to completely eradiacte tumors ${ }^{19}$. In addition, it has been observed that the in vitro anticancer activity assessment of some metallodrug candidates in relevant cancer cell lines does not always translate to an antitumoral activity in vivo ${ }^{20}$. These observations suggest that owing to the overall focus to develop novel metallodrugs, which involves their synthesis, purification, structural characterization and the assessment of their biological activity as well as elucidating their mechanism of action ${ }^{21-23}$, comparatively less attention is being directed toward understanding their biochemical fate in the bloodstream ${ }^{24}$ and the biomolecular basis of their adverse side effects ${ }^{13}$.

Studies that provide insight into the biochemical fate of novel metallodrugs in the extremely ligand rich environment of the bloodstream, however, are urgently needed to estimate their clinical potential. Owing to the fact that blood is comprised of equal volumes of plasma and red blood cells (RBCs), it is equally important to understand a metallodrugs fate in each of these compartments. Despite this, considerably less is known about the uptake of metallodrugs by $\mathrm{RBCs}^{25}$, even though the sequestration of the metallodrug therein will dramatically decrease the probability that sufficient amounts are able to reach the intended tumor tissue.

With regard to the interaction of a novel metallodrug with plasma, it is important to gain insight into its temporal degradation/hydrolysis therein and to understand the subsequent binding of the parent drug and all formed metabolites to plasma proteins as all metal-species will subsequently interact with the tumor cells (intended toxic effect) and healthy tissue cells (unintended side effects). While irreversible binding of any given metallodrug and/or its degradation/hydrolysis product(s) to abundant plasma proteins, such as human serum albumin (HSA) often decreases the probability that sufficient amounts are able to reach target cells ${ }^{26}$, it is important to point out that certain metallated plasma proteins have been demonstrated to exert the desired anticancer activity in vivo ${ }^{27}$. These findings exemplify our limited understanding of the biomolecular processes which govern the uptake of metallodrugs by cancer cells, which is a fundamental prerequisite to develop metallodrugs that exert the desired tumor selectivity ${ }^{28}$.
To improve our rather fragmentary understanding of the role that plasma proteins play in terms of delivering intravenously injected metallodrugs to target and non-target cells ${ }^{29}$, in vitro studies can provide valuable insight. Despite this, comparatively few studies have been investigated the metabolism of established metallodrugs in blood plasma to date ${ }^{30}$, let alone metallodrugs that are in devleopment. ${ }^{29}$ While studies which probe the behavior of a metallodrug in plasma can inherently neither provide information about its overall tumor selectivity (this is solely determined by its relative uptake by cancer cells vs healthy tissue cells) nor about its potential side effects (this is determined by the toxicity of all metal-containing metabolites on healthy tissue cells), they do allow to establish two important pharmacological parameters. Firstly, such studies can establish the stability of any given metallodrug in plasma, which allows one to estimate the probability of it reaching the intended target cells in a patient intact. For example, if $<10 \%$ of the parent metallodrug degrade in plasma within $1 \mathrm{~h}$ at $37^{\circ} \mathrm{C}, \sim 90 \%$ can in principle reach the intended target tissue (i.e. the tumor), provided that it is not sequestered in RBCs or inactivated by irreversibly binding to abundant plasma proteins (e.g. HSA). Secondly, the rapid formation of metalcontaining degradation/hydrolysis products after the addition of a metallodrug to plasma increases the probability that some of the formed metal-containing degradation products may be even more toxic than the parent metallodrug and therefore cause severe side-effects because they will interact with healthy tissue cells in vivo. Thirdly, the plasma protein binding of a metallodrug can provide important insight as to how it enters target cells ${ }^{22}$. These three parameters are eminently useful in the context of advancing more metallodrugs to the market ${ }^{31}$, especially if some information about the toxicity of known degradation products is already available ${ }^{32-33}$. Accordingly, the application of tools that allow to observe the fate of novel metallodrug candidates in plasma puts one in a position to advance the most promising ones (i.e. high stability of parent metallodrug, minimal degradation/hydrolysis, binding to a protein that facilitates metallodrug-uptake into target cells) to more costly in vivo animal studies and preclinical studies in human patients.

The indispensable role that modern bioanalytical techniques play in the context of gaining insight into the interaction of metallodrugs in blood plasma has been comprehensively reviewed by others ${ }^{34-40}$. While capillary electrophoresis hyphenated to inductively coupled plasma-mass spectrometry (ICP-MS) ${ }^{41}$ and size-exclusion chromatography (SEC) coupled to ICP-MS ${ }^{42}$ have been used most extensively, we will first summarize the development of another useful analytical method, namely SEC hyphenated with an inductively coupled plasma atomic emission spectrometer (ICP-AES) to observe the fate of metallodrugs in blood plasma ${ }^{43-44}$. After presenting some results that were obtained by employing this metallomics tool to probe the metabolism of cisplatin (1) and carboplatin (2) in blood plasma, the results that were obtained for two novel platinum-based drugs that exhibit promising anticancer activity $(3,4)$ will be presented. Thereafter, we will highlight how SEC-ICP-AES was used to observe the modulation of the metabolism of cisplatin with sulfur-containing biomolecules to possibly transform this Ptbased drug into a safer and more effective metallodrug. Last but not least, we will synopsize results which were obtained by applying the developed metallomics tool to simultaneously 
probe the fate of cisplatin and the Ru-containing complex NAMI-A (5) in plasma and then present some more recent results into the stability of a $\mathrm{Au}$ and Ti-containing bimetallic anticancer active complex in plasma (6).<smiles>N[PH](N)(N)Cl</smiles>

1<smiles>N[PH]1(N)OC(=O)C2(CCC2)C(=O)O1</smiles>

2

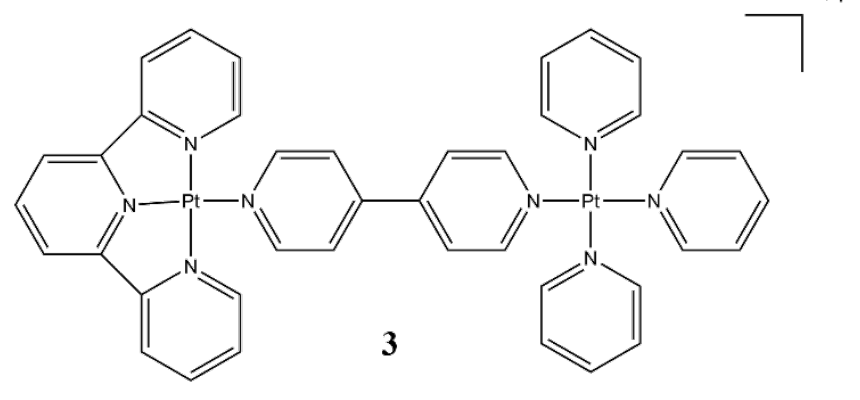

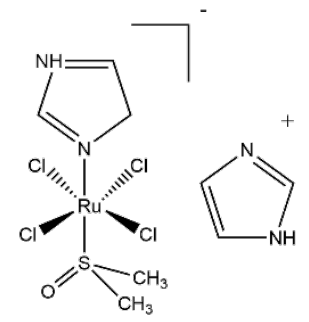

4<smiles>C=C/C(=C/C)C(=O)O[C@](C)(C1(C)CCCC1)C12CCC(CC1)C2</smiles>

5

Figure 1 Structure of metallodrugs whose fate in blood plasma was investigated with a developed metallomics method in vitro.

\subsection{Development of a metallomics method to detect $\mathrm{Cu}, \mathrm{Fe}$ and $\mathrm{Zn}$-containing metalloproteins in blood plasma}

Motivated by the desire to explore the potential of disease biomarkers that are contained in plasma, we developed an analytical method to detect endogenous metalloproteins therein. By solely focusing on metalloproteins, we dramatically simplified the analytical separation problem that is associated with separating $>5000$ plasma proteins and achieved this goal by analyzing rabbit plasma $(0.5 \mathrm{~mL})$ with SEC-ICP-AES using phosphate buffered saline (PBS)-buffer as the mobile phase. After screening several SEC stationary phases, a high resolution SEC stationary phase (Superdex 200, HR10/300) was identified which was able to separate $\sim 12$ copper, iron and zinc metalloproteins, which from now on will be referred to as the 'metalloproteome' ${ }^{43}$.

The developed metallomics method was slightly modified by using an SEC column with a fractionation range of $7 \mathrm{kDa}-100$ Da to investigate the biochemical fate of arsenobetaine (7) in plasma. The latter is a non-toxic arsenic compound that is not

metabolized by humans ${ }^{45}$ and is present in seafood that is used for human consumption ${ }^{46}$. After the addition of 7 to plasma, the analysis of this mixture over a $6 \mathrm{~h}$ time period revealed a

single arsenic peak which eluted in the inclusion volume, while single $\mathrm{Cu}, \mathrm{Fe}$ and $\mathrm{Zn}$ peaks (i.e. all plasma metalloroteins) eluted in the void volume ${ }^{47}$. These results conclusively demonstrated that this arsenic compound did not bind to any plasma proteins in plasma, which provided an explanation for the rather rapid urinary excretion of 7 (within 6-9 $\mathrm{h}$ in humans) after the ingestion of seafood ${ }^{47}$. After demonstrating that PBS-buffer represents the best biochemical buffer to avoid the generation of artefacts when<smiles>C[N+](C)(C)CC(=O)O</smiles><smiles>Cc1c(O)c(=O)ccn1C</smiles><smiles></smiles>

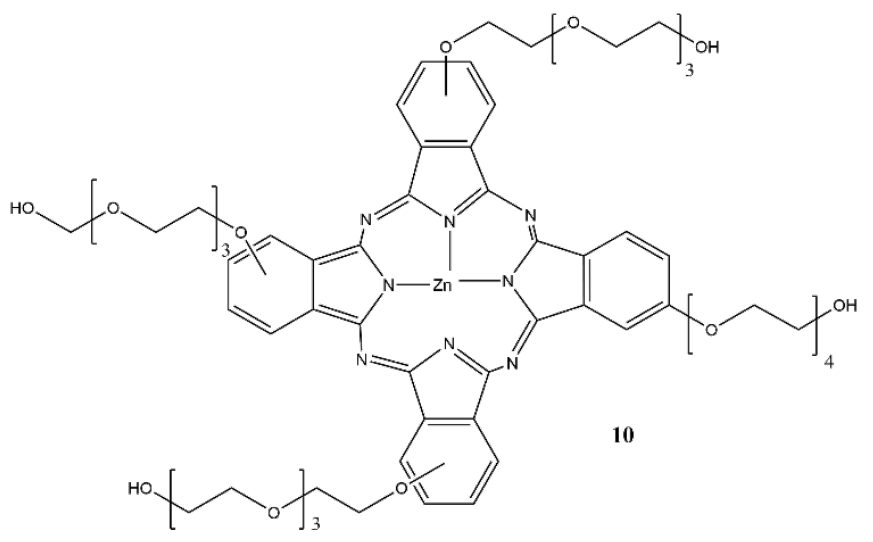

Figure 2 Structure of metal/metalloid compounds and iron chelation therapy drugs whose biochemical fate in plasma was investigated with a developed metallomics method

blood plasma is to be analyzed for metalloproteins ${ }^{48}$, the metallomics method was employed to observe the metalloproteome of human plasma, which revealed a similar number of metalloproteins compared to rabbit plasma ${ }^{49}$. While the retention times of most metalloproteins were identical in rabbit and human plasma [e.g. $\alpha_{2}$ macroglobulin $(\mathrm{Zn})$, ceruloplasmin $(\mathrm{Cu})$, transferrin $(\mathrm{Fe})$, serum albumin $(\mathrm{Cu}, \mathrm{Zn})]$, notable differences were observed for one iron metalloprotein, which was assigned to ferritin $(\mathrm{Ft})$. The strikingly different retention times that were obtained for Ft in rabbit and human plasma ( $>100 \mathrm{~s})$ were difficult to rationalize at the time, but were eventually resolved when this iron metalloprotein was recently unequivocally identified as a haptoglobin-hemoglobin $(\mathrm{Hp}-\mathrm{Hb})$ complex ${ }^{50}$. This $\mathrm{Hp}-\mathrm{Hb}$ complex is rapidly formed in plasma when hemoglobin is released from RBC's and subsequently binds to the plasma protein $\mathrm{Hp}$. The formation of the $\mathrm{Hp}-\mathrm{Hb}$ complex is of 
considerable health relevant as its formation protects the kidneys from the toxicity of free $\mathrm{Hb}$ in plasma ${ }^{51}$.

In an effort to explore the inherent potential of the metallomics method to visualize pharmacologically relevant processes that involve metals in plasma, it was employed to compare the effect of the iron-chelation therapy drugs deferiprone (DFP, 8) and desferrioxamine $\mathrm{B}$ (DFO, 9) on the plasma metalloproteome ${ }^{52}$. After the addition of equimolar and pharmacologically relevant doses to human plasma (male healthy volunteer), the analysis of the latter revealed that $\mathbf{8}$ mobilized $\sim 34 \%$ of $\mathrm{Fe}$ from the iron peak that corresponds to transferrin (Tf)(the intensity of the other iron peak remained unchanged), which was $\sim 8$-fold more than was mobilized of iron by 9. These findings were in accord with previous observations by others ${ }^{53}$ and can be rationalized based on the fact that $\mathbf{8}$ is considerably smaller than $\mathbf{9}$ and can therefore more easily access the $\mathrm{Fe}^{3+}$ binding sites on $\mathrm{Tf}$. The iron species that eluted in the inclusion volume was identified as (DFP) $)_{3} \mathrm{Fe}$ by ESI-MS, which is likely the iron species that is likely excreted in urine via the kidneys. Interestingly, however, the $\mathrm{Zn}$-specific chromatograms - which were obtained simultaneously with the Fe-specific chromatograms - revealed that 8 and 9 also mobilized zinc from zinccontaining plasma metalloproteins, predominantly HSA, which is known to contain several weak $\mathrm{Zn}^{2+}$ binding sites. In fact, 8 was twice as 'effective' in abstracting $\mathrm{Zn}$ from zinc metalloproteins compared to $9^{52}$ and the zinc species that eluted in the inclusion volume could be identified as a (DFP) ${ }_{2} \mathrm{Zn}$ complex. Since the latter complex is known to be readily excreted in mammalian urine, ${ }^{54}$ the long-term treatment of iron overload patients (e.g. those suffering from hereditary hemochromatosis) with $\mathbf{8}$ is known to induce zinc deficiency ${ }^{55}$, which is why patients are given zinc supplements during treatment. These results demonstrate that the metallomics method has revealed an iron-chelation therapy drug-mediated mobilization of zinc from plasma metalloproteins, which essentially represents a side-effect of 8 and 9.

We next employed the metallomics method to investigate the fate of a water-soluble tetraethyleneglycol-substituted $\mathrm{Zn}$ (II) phthalocyanine compound (10), which exhibited the desired photochemical properties for it to be used as a photodynamic therapy drug, in human plasma ${ }^{56}$. After adding a pharmacologically relevant dose of $\mathbf{1 0}$ to plasma, the analysis of the latter over a $3 \mathrm{~h}$ period revealed that $\mathbf{1 0}$ did not bind to plasma proteins (e.g. HSA), but eluted in the small molecular weight elution range ${ }^{56}$. These results clearly demonstrated that if patients were to be intravenously injected with 10, the latter would be able to diffuse into organs where the intended photochemical activity could then be induced.

Collectively, the aforementioned results conclusively demonstrated that the metallomics method can be employed to i) determine the plasma metalloproteome, which has inherent diagnostic value ${ }^{50}$, ii) probe the plasma protein binding of exogenous metal-containing compounds and complexes $(7,10)$ in plasma and iii) observe the comparative mobilization of iron and zinc from plasma metalloproteins by clinically used chelation therapy drugs $(\mathbf{8}, \mathbf{9})$. Encouraged by this unique capability to probe pharmacologically relevant events in whole plasma and considering the important role that plasma proteins play in the delivery of metallodrugs to cancerous tissue ${ }^{57-58}$, we applied it to probe the metabolism of anticancer metallodrugs in human plasma.

1.3. Application of the metallomics method to probe the metabolism of Pt-based anticancer drugs in human plasma

Since most clinically used platinum-based drugs are intravenously administered to cancer patients, we applied the metallomics method to gain insight into their metabolism in plasma after adding pharmacologically relevant doses of cisplatin (1) and carboplatin (2). The mixtures were incubated at $37^{\circ} \mathrm{C}$ and analyzed after $5 \mathrm{~min}, 3 \mathrm{~h}$ and $24 \mathrm{~h}$ (Figure 3$)^{30}$. Unexpectedly, 1 eluted past the inclusion volume (Figure 3A, small molecular weight species elution range), which implied a strong interaction of the intact drug with the stationary

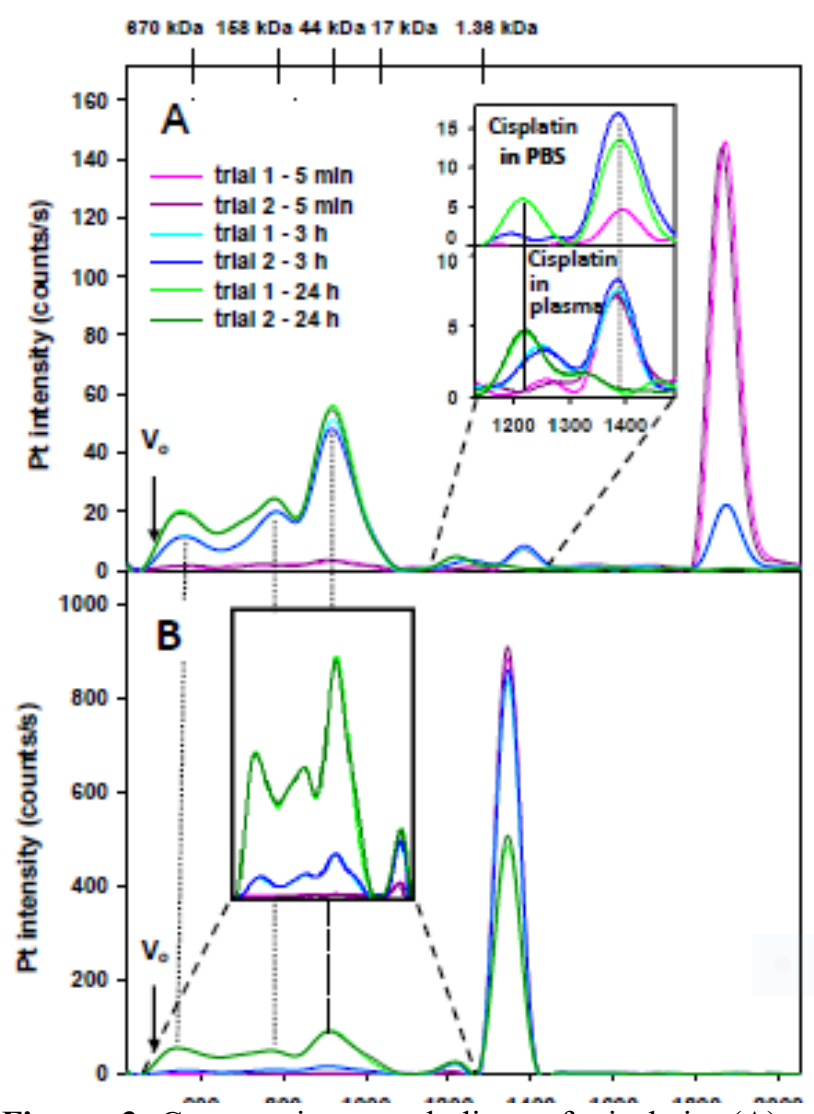

Figure 3 Comparative metabolism of cisplatin $(\mathbf{A})$ and carboplatin (B) after adding pharmacologically relevant doses to human plasma. ${ }^{30} \mathrm{~V}_{0}=$ void volume phase.

This seemingly counterproductive observation, however, turned out to be a blessing in disguise as it allowed us to comprehensively observe the metabolism of $\mathbf{1}$ as dynamic changes of the plasma concentration of the parent Pt-drug (Ptpeak eluting past the inclusion volume), cisplatin-derived hydrolysis products (Pt-peaks eluting near the inclusion volume) and platinated plasma proteins (Pt-peaks eluting in the protein elution range) could be observed (Figure 3A). After $5 \mathrm{~min}, 6.5 \%$ of Pt was plasma protein bound (three plasma proteins), $4.6 \%$ eluted in form of a hydrolysis product and $89 \%$ eluted as the parent drug. These results demonstrate that $\mathbf{1}$ is metabolized much faster than $\mathbf{2}$ (Figure 3B) for which no plasma protein binding was observed at this time point, 
although an apparent hydrolysis product was observed $(0.5 \%$ of total $\mathrm{Pt}$ ) and $99.4 \%$ eluted as the parent drug. $3 \mathrm{~h}$ after $\mathbf{1}$ was added to plasma, $76 \%$ of $\mathrm{Pt}$ was plasma protein bound, $8.2 \%$ eluted in form of two hydrolysis products and $16 \%$ as the parent drug. After $24 \mathrm{~h}, 95 \%$ of $\mathrm{Pt}$ was plasma protein bound (three plasma proteins) and the remainder eluted in form of a hydrolysis product. Thus, the dynamic metabolism of $\mathbf{1}$ and $\mathbf{2}$ could be comprehensively observed and no significant differences between their metabolism in blood plasma from men and women was noticeable ${ }^{30}$.

Most importantly, the metabolism of $\mathbf{1}$ differed significantly from that of 2 for which even after $24 \mathrm{~h}$ still $58 \%$ of Pt eluted as the parent drug, $\sim 3 \%$ in form of a hydrolysis product and the remainder eluted plasma protein bound. Since all Ptmetabolites that are formed in blood plasma will subsequently interact with RBC's, cancer cells and healthy tissue cells, the strikingly different degradation/hydrolysis of $\mathbf{1}$ and $\mathbf{2}$ can also explain their strikingly different side effects in patients ${ }^{30}$. To this end, a more detailed comparison of the metabolism of these clinically used anticancer drugs revealed that the first hydrolysis product that was detected for 1 (HP1) increased from $4.6 \%$ of total $\mathrm{Pt}$ at the $5 \mathrm{~min}$ time point to $5.6 \%$ at the 3 $\mathrm{h}$ time point, but was entirely absent after $24 \mathrm{~h}$ (only proteinbound Pt was observed). Based on previous studies by others, $\mathrm{HP} 1$ is tentatively identified as $\left[\mathrm{PtCl}\left(\mathrm{OH}_{2}\right)\left(\mathrm{NH}_{3}\right)_{2}\right]^{+26}$ and is a critical metabolite in the metabolism of 1 in plasma because it has been shown to be 8-times as toxic as the parent drug ${ }^{32-33}$. This observation suggests that the rapid formation of HP1 in blood plasma is likely to contribute to the severe toxic side effects of 1 after it is intravenously administered to cancer patients, which is in stark contrast to the common belief that HP1 is only formed in the cytosol ${ }^{59}$. Another hydrolysis product (HP2) was already present at the $3 \mathrm{~h}$ time point for $\mathbf{2}$, but only at the $24 \mathrm{~h}$ time point for 1 . One must consider, however, that a higher dose was used for 2 than for $\mathbf{1}$. Both the $\mathbf{1}$ and 2-derived hydrolysis products appeared to bind to the same plasma proteins (Figure 3 ).

The fact that the observed hydrolysis for $\mathbf{1}$ and $\mathbf{2}$ in plasma was in sync with literature data prompted us to investigate the biochemical fate of novel Pt-based anticancer drugs $(3,4)$ in rabbit blood plasma ${ }^{60}$. These particular Pt-complexes were chosen out of a set of 17 structurally diverse (2,2';6'2"terpyridine)platinum(II) complexes and a 1,10-phenanthrone Pt-derivative based on their different stability in the presence of glutathione (GSH), which was determined by their observed $\mathrm{t}^{1 / 2}$ in the presence of $8 \mathrm{mM} \mathrm{GSH}$ using ${ }^{1} \mathrm{H}-\mathrm{NMR}$ spectroscopy. While 3 readily reacted with $\mathrm{GSH}\left(\mathrm{t}^{1} / 2<1 \mathrm{~min}\right)$, 4 remained stable in the presence of excess GSH $\left(\mathrm{t}^{1 / 2}=68 \mathrm{~h}\right)$. After the addition of pharmacologically relevant doses of 3 and $4(100 \mu \mathrm{M})$ to rabbit plasma, its analysis after $5 \mathrm{~min}$ and $60 \mathrm{~min}$ revealed essentially identical results for both time points (Figure 4), but entirely different plasma protein binding profiles for 3 and 4. The co-elution of 3 with HSA/Tf - these plasma proteins are not separated on the SEC column - was rationalized by the rapid formation of protein adducts, while 4 eluted as a single Pt-peak past the inclusion volume (similar to 1 in Figure 3). The distinct differences in the plasma protein binding of $\mathbf{3}$ and $\mathbf{4}$ were rationalized based on their notably different interaction with rabbit serum albumin (RSA), which contains a thiol group (cysteine 34). Although these results do not definitively prove that $\mathbf{3}$ binds to $\mathrm{Tf}$, it is at least possible that the latter plasma protein may facilitate its uptake by cancer cells via receptor-mediated endocytosis.
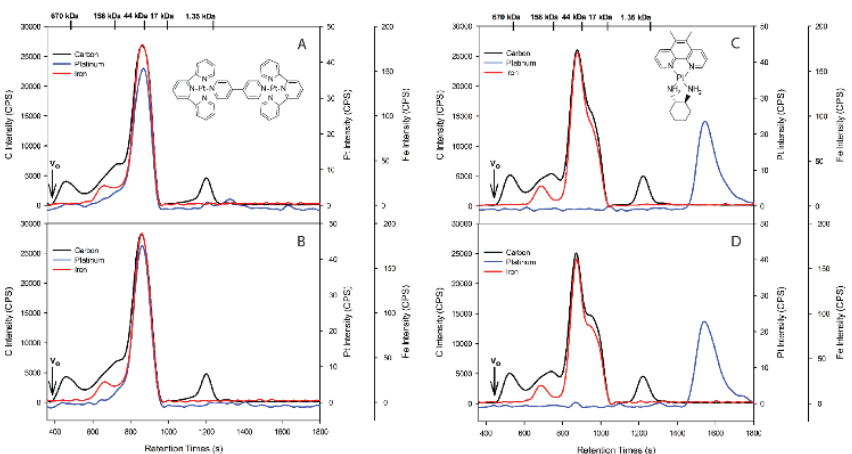

Figure 4 Comparative plasma protein binding of platinum complexes 3 (left) and $\mathbf{4}$ (right) in rabbit plasma after $5 \mathrm{~min}$ $(\mathrm{A}, \mathrm{C})$ and $60 \mathrm{~min}$ incubation $(\mathrm{B}, \mathrm{D})$ at $37^{\circ} \mathrm{C}{ }^{60}$

Conversely, 4 did not bind to plasma proteins, which suggests that - owing to the hydrophobic nature of the phenanthroline moiety - it can be uptaken into cells by passive diffusion, similar to $1,{ }^{61}$ or by OCT transporters owing to the +2 charge. These results exemplify that metallomics-derived results allow one to gain insight into the mechanisms by which a metallodrug may enter cancer cells. Considering that the binding of a metallodrug to $\mathrm{Tf}$ and the uptake of the formed complex via receptor-mediated endocytosis represents a viable drug delivery strategy, ${ }^{62}$ improvements in the chromatographic separation of HSA and Tf are urgently needed to decrease the ambiguity of the results. To this end, SEC stationary phases which offer the desired fraction range and have a particle size of $3 \mu \mathrm{m}$ are available, but their potential to separate HSA from Tf after the injection of plasma has not been investigated.

\subsection{Application of the metallomics method to probe the modulation of the metabolism of cisplatin in human plasma with sulfur-containing biomolecules}

Owing to the comparatively rapid hydrolysis of $\mathbf{1}$ in blood plasma to form a highly toxic hydrolysis product (HP1) and given that previous animal studies had shown that its toxicity can be ameliorated by so-called 'ameliorating agents', which are small molecular weight sulfur compounds ${ }^{29}$, 63, it is perhaps surprising that comparatively little was known about the location and the nature of the biomolecular events that can explain these observations. We therefore employed the metallomics method to investigate if the molecular basis for these observations unfolds in plasma and if this were the case, if insight into the underlying mechanism could be obtained. While we systematically investigated the modulation of the metabolism of 1 by sodium thiosulfate (STS) ${ }^{64}$, D-methionine ${ }^{65}, \mathrm{~N}$-acetyl-L-cysteine ${ }^{66}$ and glutathione ${ }^{67}$ in plasma, only the results that were obtained with STS will be described.

Since a molar STS:1 ratio of 400:1 had been previously demonstrated to be most effective in minimizing toxic effects in animal studies, we employed this ratio in our in vitro studies. After spiking plasma with a pharmacologically relevant dose of 1 and incubating the mixture for $10 \mathrm{~min}$ $\left(37^{\circ} \mathrm{C}\right)$, STS was added and the mixture was incubated for another $10 \mathrm{~min}$ before it was analyzed (Fig. 5A, red trace). The results revealed the presence of $\mathbf{1}$ as well as two nonbaseline separated Pt-peaks, which eluted close to the 


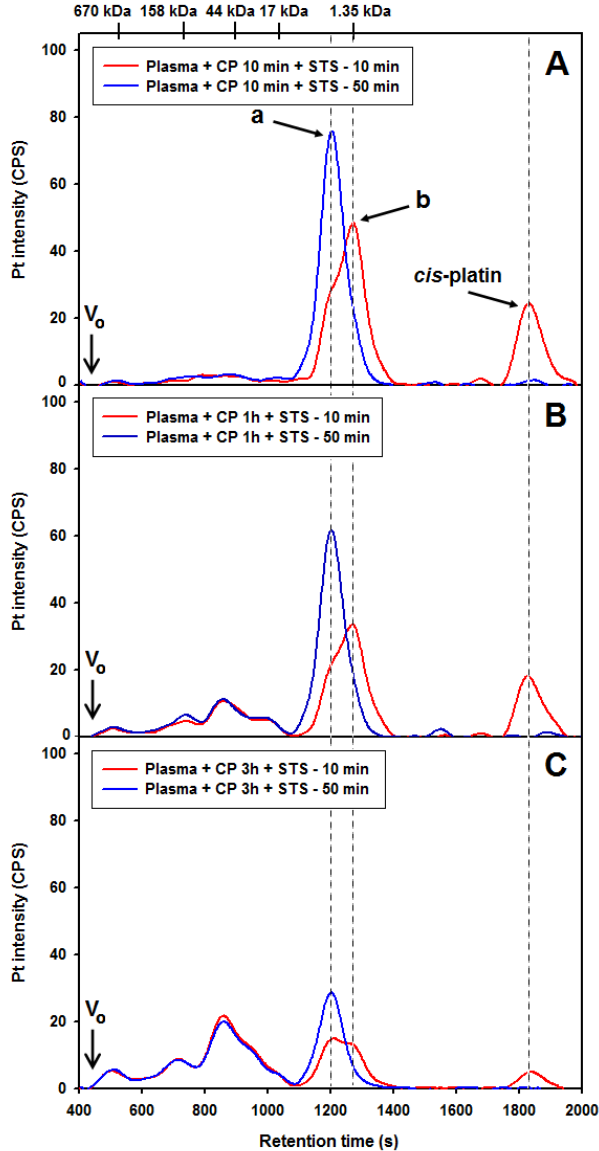

Figure 5 Pt-specific chromatograms obtained after the addition of $\mathbf{1}$ and STS to human plasma and analysis with the metallomics method. ${ }^{64} \mathbf{V}_{\mathbf{0}}=$ void volume

inclusion volume. Then the experiment was repeated, but plasma that had been spiked with 1 for 10 min was now incubated for 50 min after STS had been added (Fig. 5A, blue trace). The results revealed that a minor Pt-fraction was bound to plasma proteins. An intense Pt-peak was detected which had a different retention time than any of the hydrolysis product of 1 . Extending the plasma incubation time after 1 was added to $1 \mathrm{~h}$ (Fig. 5B) and $3 \mathrm{~h}$ (Fig. 5C) before STS was added revealed the same $\mathrm{Pt}$-peaks that eluted close to the inclusion volume, but they became progressively less intense. Concomitantly, the fraction of $\mathrm{Pt}$ that eluted bound to plasma proteins increased.

Based on the metabolism of $\mathbf{1}$ in plasma (Figure 3), the modulation of its metabolism by STS (Figure 5) can be rationalized in terms of the rapid reaction of a hydrolysis product of 1 with STS to initially form two Pt-STS complexes (10 $\mathrm{min})$ and the eventual formation of one Pt-STS complex which eluted at retention time of $1200 \mathrm{~s}$ (50 min). The Pt-STS complex that was preset after 50 min could be isolated and

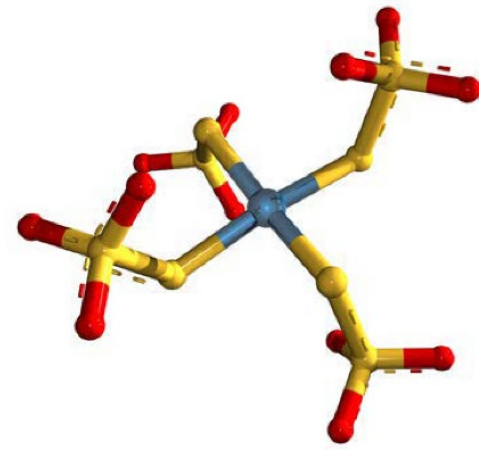

Figure 6 Structure of $\left[\mathrm{Pt}\left(\mathrm{S}_{2} \mathrm{O}_{3}\right)_{4}\right]^{6-}$ complex that is formed in blood plasma after the addition of $\mathbf{1}$ and STS at a molar ratio of $1: 400{ }^{69}$

(Fig. 6).

The results that were obtained for the modulation of the metabolism of $\mathbf{1}$ in human plasma by STS and the other 'ameliorating agents' revealed that each of these small molecular weight sulfur compounds targets the highly reactive $\left[\mathrm{PtCl}\left(\mathrm{OH}_{2}\right)\left(\mathrm{NH}_{3}\right)_{2}\right]^{+}$species to form novel platinumsulfur species, two of which could be structurally characterized. ${ }^{65,68}$ Taken together, the results of these investigations revealed that it is feasible to identify an ideal small molecular weight sulfur compound that can be coadministered with 1 to neutralize the highly toxic HP1, while leaving its anticancer effect largely intact ${ }^{14,69}$.

Considering that blood plasma of cancer patients often contains significantly lower HSA concentration compared to healthy controls and in view of the important role that this plasma protein plays in the metabolism of $\mathbf{1}$, the metallomics method was also employed to compare it's metabolism in plasma from pediatric cancer patients with that in plasma from healthy controls ${ }^{15}$. Indeed, blood plasma of pediatric cancer patients $(n=11)$ contained $26 \pm 7 \mathrm{~g} \mathrm{HSA} / \mathrm{L}$, while that of healthy adults $(n=20)$ contained $42 \pm 4$ g HSA/L. After the addition of the same pharmacologically relevant dose of $\mathbf{1}$ to plasma aliquots from both groups, the mixtures were incubated at $37^{\circ} \mathrm{C}$ for $2 \mathrm{~h}$ and then analyzed. These results revealed a $5.9 \%$ increase of toxic hydrolysis products of $\mathbf{1}$ in pediatric plasma, while $9.8 \%$ less $\mathrm{Pt}$ was plasma protein bound compared to the healthy adults. These results demonstrate that at least in vitro the comparatively elevated concentration of hydrolysis products of $\mathbf{1}$ in plasma from pediatric patients may contribute to the toxic side-effects in cancer patients. To demonstrate that the metabolism of 1 can be modulated we added pure HSA to pediatric cancer plasma to boost its HSA concentration to 36 and $42 \mathrm{~g} \mathrm{HSA} / \mathrm{L}$. The addition of 1 , followed by the $2 \mathrm{~h}$ incubation and the analysis revealed that the concentration of HP1 decreased from $4.2 \%$ to $1.8 \%$ and that of HP2 from $17 \%$ to $11.1 \%$ of total Pt. The formation of the highly toxic hydrolysis product (HP1), however, could not be entirely prevented. These in vitro results strongly suggest that boosting the plasma concentration of cancer patients with pure HSA can ameliorate the sever toxic side-effects if $\mathbf{1}$, but not completely prevent the formation of the highly toxic HP1. Based on these investigations into the modulation of the metabolism of $\mathbf{1}$, its deliberate modulation with small molecular weight sulfur compounds is the most promising strategy to improve its 
safety, while leaving its efficacy largely intact (see intact 150 min after the addition of STS to plasma (Figure 5A-C).

\subsection{Application of the metallomics method to probe the metabolism of two different metallodrugs and a bimetallic metal complex in human plasma}

One major problem that is frequently encountered during the treatment of cancer patients with a single anticancer drug is the development of resistance, which can be caused by the active expulsion of the glutathione-drug conjugates from cancer cells by ATP-driven export pumps ${ }^{70}$. To circumvent the development of drug resistance, the co-administration of two drugs that target different biochemical pathways has been shown to be a promising approach ${ }^{71}$. This so-called 'combination therapy' approach can also increase the effectiveness of the treatment. Indeed, the treatment of tumorimplanted mice with $\mathbf{1}$ and the ruthenium-containing metallodrug 5 (new antitumor metastasis inhibitor A or NAMI-A) was twice as effective in as the treatment with either drug alone ${ }^{72}$. Since $\mathbf{1}$ and $\mathbf{5}$ are intravenously administered to humans and since both are known to interact with plasma proteins ${ }^{73}$, it is important to assess whether these metallodrugs may mutually affect their plasma protein binding which may reduce their overall effect. The metallomics tool was therefore employed to simultaneously observe the emission lines of $\mathrm{Pt}$ and $\mathrm{Ru}$ to investigate if the order of addition of equimolar and pharmacologically relevant doses of $\mathbf{1}$ and $\mathbf{5}$ to human blood plasma adversely affects their plasma protein binding profiles over a $2 \mathrm{~h}$ period ${ }^{74}$. The results revealed no perturbation of the metabolism of each metalbased drug was observed regardless of the order of addition of the other metallodrug. These results imply that each metallodrug-derived metal species bind to different binding sites on HSA, which implies that each metallodrug should be able to reach the cancer tissue cells if they are not sequestered by RBCs and that further clinical studies to explore combination therapy with these particular metal-based drugs are warranted. Thus, conceptually straightforward in vitro studies with human plasma can establish the foundation to conduct preclinical studies.

Last but not least, the metallomics method was also applied to investigate the stability of a bimetallic anticancer drug Titanocene (6) in human plasma ${ }^{75}$. After the addition of a pharmacologically relevant dose $(152 \mu \mathrm{M})$ to human plasma, the mixture was incubated at $37^{\circ} \mathrm{C}$ and simultaneously analyzed for $\mathrm{Au}, \mathrm{Ti}$ and S-species after 5 and $60 \mathrm{~min}$. The results revealed that $70 \%$ of the intact drug irreversibly bound to the stationary phase (60 min time point) and revealed a $\mathrm{Ti}$ degradation product that eluted partially, and a $\mathrm{Au}$ degradation product that eluted entirely bound to plasma proteins (both time points). Based on the obtained results it was possible to establish - for the first time - its likely degradation pathway in human plasma in vitro (Figure 7). Accordingly, $\sim 70 \%$ of 6 remain in human plasma after 60 min, which is in excellent accord with results from an in vivo study with mice which were treated with 6 and revealed Ti:Au molar ratios in tumors and organs close to $1: 1$. Thus, metallomics studies can provide important insight into the stability of bimetallic complexes, which suggest that the intact drug is likely to reach target tissue. Overall, our results exemplify that the execution of intermediate in vitro studies with human plasma can play an important role in advancing bimetallic metal-based drugs to more costly clinical studies.

\section{Challenges}

While studies that aim to establish the biochemical fate of novel metallodrugs in blood plasma and/or RBC lysate can provide important data to estimate its probability of reaching the target tissue, one should be aware of two important bottlenecks. The first one is to establish a reliable source of human blood plasma/serum or RBC lysate of sufficient quality. We have decided to produce a human plasma stock for most of our studies, which requires the approval by an ethics committee. A viable alternative to human plasma is to use rabbit plasma from New Zealand white rabbits, which is available from commercial vendors. However, one needs to ascertain that the plasma product is of sufficient quality.

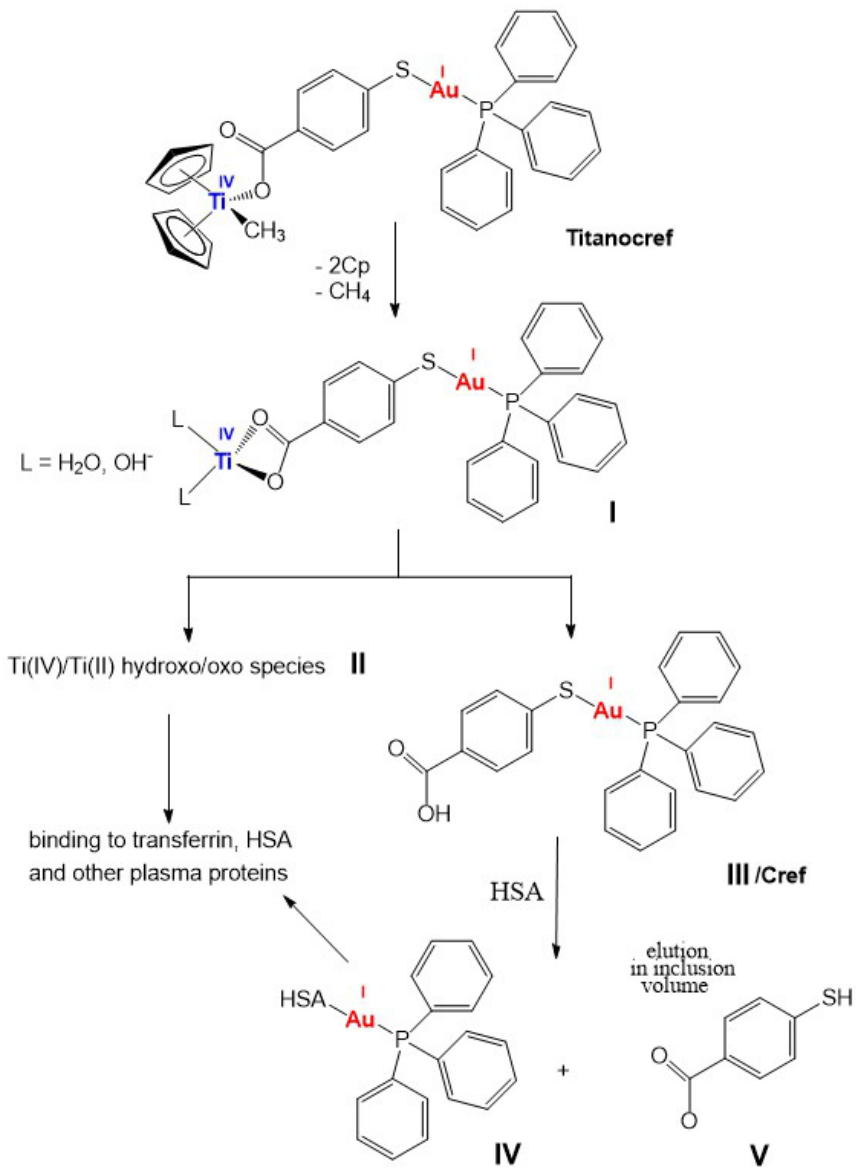

Figure 7 Proposed degradation pathway for the bimetallic anticancer complex $\mathbf{6}$ in human plasma based on the addition of a pharmacologically relevant dose to human plasma (152 $\mu \mathrm{M}$ ) followed by its analysis with the developed metallomics method. ${ }^{75}$

For example, important details of the rabbit plasma must be provided by a vendor (e.g. anticoagulant used, plasma pool of different animals vs plasma from a single animal, plasma filtered, etc.). We have demonstrated that after the addition of the same pharmacological dose of $\mathbf{1}$ to human and rabbit plasma, its metabolism over a $24 \mathrm{~h}$ period was essentially identical (data not shown). With regard to establishing a source for RBC lysate stock and owing to the difficulty of finding a commercial vendors, we established an RBC stock. While this requires an approved ethics protocol to harvest the required volume of whole blood, one must be aware of the fact that the cell membrane debris is not completely removed by centrifugation and will adversely affect the SEC separation. It 
was therefore necessary to develop a sample preparation procedure which involved the filtration of the RBC lysate through an appropriate filter (Millex HV $0.45 \mu \mathrm{m}$ pore size) before injection. ${ }^{76}$

Another challenge is the fact that the employed SEC stationary phase may not be entirely innocuous/inert. While this must not neccessarily be a problem (see the elution of $\mathbf{1}$ past the inclusion volume in Fig. 3A and of 4 in Figure 4C and D), the employed Superdex 200 Increase SEC stationary phase did not allow us to observe the elution of $\mathbf{6}$ from this column intact regardless whether it was added to blood plasma or PBS-buffer and then analyzed. This behavior was attributed to the formation of hydrogen bonds between the carbonyl group of $\mathbf{6}$ with $\mathrm{OH}$-groups of the stationary phase. Although this strong interaction resulted in its complete binding to the stationary phase, the obtained results nevertheless allowed us to conclude that $\sim 70 \%$ of the intact drug remained in human plasma intact $60 \mathrm{~min}$ after it was added (i.e. $30 \%$ of the injected drug eluted in form of $\mathrm{Ti}$ and Au-containing degradation products). Despite this, we continue to screen novel SEC stationary phases that do not contain OH-groups in their backbone to facilitate studies into the stability of metallodrugs in blood plasma.

\section{Conclusion}

Our limited understanding of the fate of novel metallodrugs in the bloodstream translates to an overall inability to estimate their probability of reach the intended cancer target tissue intact. Since this fundamental bottleneck hampers the acceleration of more metallodrugs to preclinical studies, increasing research efforts should be directed at employing appropriate metallomics methods to better understand their biochemical fate in blood plasma and RBC's. To this end, we have successfully employed a metallomics method to observe the metabolism of individual metallodrugs in blood plasma, to observe the modulation of the metabolism of a clinically used metallodrug by sulfur-containing species and to simultaneously probe the metabolism of two metallodrugs that contained two different metals and a bimetallic metallodrug in plasma. The versatility of this metallomics method to simultaneously detect a large array of metals makes it ideally suited to be employed in studies that aim to screen novel metallodrugs for their stability in plasma and to reveal possible molecular mechanism(s) by which they are delivered to target cells (Tf-mediated drug delivery vs passive diffusion). The application of this powerful metallomics tool in conjunction with other established instrumental techniques, such as X-ray absorption spectroscopy (XAS) and electrospray ionization mass spectrometry (ESI-MS) is bound to play an increasingly important role in harnessing the full potential of metallodrugs to accelerate more of them to preclinical studies in the future. ${ }^{77-80}$

\section{CONFLICT OF INTEREST}

The authors declare no conflict of interest.

\section{References}

1. Cohen, J. D.; Li, L.; Wang, Y.; Thoburn, C.; Afsari, B.; Danilova, L.; Douville, C.; Javed, A. A.; Wong, F. S. H.; Mattox, A.; Hruban, R. H.; Wolfgang, C. L.; Goggins, M. G.; Molin, M. D.; Wang, T.-L.; Roden, R.; Klein, A. P.; Ptak, J.; Dobbyn, L.; Schaefer, J. K.; Silliman, N.; Popoli, M.;
Vogelstein, J. T.; Browne, J. D.; Schoen, R. E.; Brand, R. E.; Tie, J.; Gibbs, P.; Wong, H.-L.; Mansfield, A. S.; Jen, J.; Hanash, S. M.; Falconi, M.; Allen, P. J.; Zhou, S.; Bettegowda, C.; Diaz, L. A. J.; Tomasetti, C.; Kinzler, K. W.; B., .; Lennon, A. M.; Papadopoulos, N., Detection and localization of surgically resectable cancers with a multianalyte blood test. Science 2018, 359, 926-930.

2. Hartinger, C. G.; Dyson, P. J., Bioorganometallic chemistry-from teaching paradigms to medicianl applications. Chem. Soc. Rev. 2009, 38, 391-401. 3. $\quad$ Kamangar, F.; Dores, G. M.; Anderson, W. F., Patterns of cancer incidence, mortality, and prevalence across five contrinents: defining priorities to reduce cancer disparities in different geographi regions of the world. J. Clin. Oncol. 2006, 24, 2137-2150.

4. Poirier, A. E.; Ruan, Y.; Walter, S. D.; Franco, E. L.; Villeneuve, P. J.; King, W. D.; Volesky, K. D.; O'Sullivan, D. E.; Friedenreich, C. M.; Brenner, D. R., The future burden of cancer in Canada: long-term cancer incidence projections. Cancer Epidemiol. 2019, 59, 199-207. 5. Mjos, K. D.; Orvig, C., Metallodrugs in medicinal inorganic chemistry. Chem. Rev. 2014, 114, 4540-4563.

6. Scott, A. M.; Wolchok, J. D.; Old, L. J., Antibody therapy of cancer. Nature Reviews Cancer 2012, 12, 278287.

7. Zitvogel, L.; Apetoh, L.; Ghiringhelli, F.; Kroemer, $G$., Immunological aspects of cancer chemotherapy. Nature Reviews Immunology 2008, 8, 59-73.

8. Wang, X.; Guo, Z., Targeting and delivery of platinum-based anticancer drugs. Chem. Soc. Rev. 2013, 42, 202-224.

9. Barry, N. P. E.; Sadler, P. J., Exploration of the medical periodic table: towards new targets. Chem. Comm. 2013, 49, 5106-5131.

10. Plumb, J. A.; Venugopal, B.; Oun, R.; GomezRoman, N.; Kawazoe, Y.; Venkataramanan, N. S.; Wheate, N. J., Curcubit[7] uril encapsulated cisplatin overcomes cisplatin resistance via a pharmacokinetic effect. Metallomics 2012, 4, 561-567.

11. Pang, C. T.; Ammit, A. J.; Ong, Y. Q. E.; Wheate, N. J., para-Sulfonatocalix[4]arene and polyamidoamine dendrimer nanocomplexes as delivery vehicles for a bovel platinum anticancer agent J. Inorg. Biochem. 2017, 176, 1-7. 12. Kratz, F.; Muller, I. A.; Ryppa, C.; Warnecke, A., Prodrug strategies in anticancer chemotherapy. ChemMedChem 2008, 3, 20-53.

13. Oun, R.; Moussa, Y. E.; Wheate, N. J., The side effetcs of platinum-based chemotherapy drugs: a review for chemists. Dalton Trans. 2018, 47, 6645-6653.

14. Gailer, J., Improving the safety of metal-based drugs by tuning their metabolism with chemoprotective agents. J. Inorg. Biochem. 2018, 179, 154-157.

15. Morris, T. T.; Ruan, Y.; Lewis, V. A.; Narendran, A.; Gailer, J., Fortification of blood plasma from cancer patients with human serum albumin decreases the concentration of cisplatin-derived hydrolysis products in vitro. Metallomics 2014, 6, 2034-2041.

16. Hambley, T. W., Metal-based therapeutics. Science 2007, 318, 1392-1393.

17. Lovejoy, K. S.; Lippard, S. J., Non-traditional platinum compounds for improved accumulation, oral 
bioavailability, and tumor targeting. Dalton Trans. 2009, 10651-10659.

18. Hambley, T. W., Transporter and protease mediated delivery of platinum complexes for precision oncology. $J$. Biol. Inorg. Chem. 2019, 24, 457-466.

19. Hambley, T. W., Developing new metal-based therapeutics: challenges and opportunities. Dalton Trans. 2007, 4929-4937.

20. Moretto, J.; Chauffert, B.; Ghiringhelli, F.; Aldrich-Wright, J. R.; Bouyer, F., Discrepancy between in vitro and in vivo antitumor effect of a new platinum(II) metallointercalator. Invest. New Drugs 2011, 29, 1164-1176. 21. Wang, Y.; Li, H.; Sun, H., Metalloproteomics for unveiling the mechanism of action of metallodrugs. Inorg. Chem. 2019, 58, 13673-13685.

22. Casini, A.; Reedijk, J., Interactions of anticancer Pt compounds with proteins: an overlooked topic in medicinal inorganic chemistry? Chem. Sci. 2012, 3, 3135-3144. 23. Groessl, M.; Dyson, P. J., Bioanalytical and biophysical techniques for the elucidation of the mode of action of metal-based drugs. Curr. Top. Med. Chem. 2011, 11, 2632-2646.

24. Ndagi, U.; Mhlongo, N.; Soliman, M. E., Metal complexes in cancer therapy - an update from drug design perspective. Drug Design, Development and Therapy 2017, 11, 599-616.

25. Mandal, R.; Kalke, R.; Li, X.-F., Interaction of oxaliplatin, cisplatin, and carboplatin with hemoglobin and the resulting release of a heme group. Chem. Res. Toxicol. 2004, 17, 1391-1397.

26. Ivanov, A. I.; Christodoulou, J.; Parkinson, J. A.; Barnham, K. J.; Tucker, A.; Woodrow, J.; Sadler, P. J., Cisplatin binding sites on human albumin. J. Biol. Chem. 1998, 273, 14721-14730.

27. Mayr, J.; Heffeter, P.; Groza, D.; Galvez, L.; Koellensperger, G.; Roller, A.; Alte, B.; Haider, M.; Berger, W.; kowol, C. R.; Keppler, B. K., An albumin-based tumor targeted oxaliplatin prodrug with distinctlyimproved anticancer activity in vivo. Chem. Sci. 2017, 8, 2241-2250. 28. Doherty, G. J.; McMahon, H. T., Mechanisms of endocytosis. Annu. Rev. Biochem. 2009, 78, 857-902.

29. Sooriyaarachchi, M. Ameliorating the toxic sideeffects of cisplatin by systematically modulating its metabolism in human plasma with chemoprotective agents. University of Calgary, Calgary, 2015.

30. Sooriyaarachchi, M.; Narendran, A.; Gailer, J., Comparative hydrolysis and plasma binding of cis-platin and carboplatin in human plasma in vitro. Metallomics 2011, 3, 49-55.

31. Hinderling, P. H., Red blood cells: a neglected compartment in pharmacokinetics and pharmacodynamics. Pharmacol. Rev. 1997, 49, 279-295.

32. Videhult, P.; Laurell, G.; Wallin, I.; Ehrsson, H., Kinetics of cisplatin and its monohydrated complex with sulfur-containing compounds designed for local otoprotective administration. Exp. Biol. Med. 2006, 231, 1638-1645.

33. van den Berg, J. H.; Beijnen, J. H.; Balm, A. J. M.; Schellens, J. H. M., Future opportunities in preventing cisplatin induced ototoxicity. Cancer Treat. Rev. 2006, 32, 390-397.
34. Timerbaev, A. R.; Hartinger, C. G.; Aleksenko, S. $S$.; Keppler, B. K., Interactions of antitumor metallodrugs with serum proteins: advances in characterization using modern analytical methodology. Chem. Rev. 2006, 106, 2224-2248.

35. Sun, X.; Tsang, C.-N.; Sun, H., Identification and characteristics of metallodrug binding proteins by (metallo)proteomics. Metallomics 2009, 1, 25-31.

36. Groessl, M.; Hartinger, C. G., Anticancer metallodrug research analytically painting the "omics" picture-current developments and future trends. Anal. Bioanal. Chem. 2013, 405, 1791-1808.

37. Sussulini, A.; Becker, J. S.; Becker, J. S., Laser ablation ICP-MS: application in biomedical research. Mass. Spectrom. Rev. 2017, 36, 47-57.

38. Barnett, J. P.; Scanlan, D. J.; Blindauer, C. A., Protein fractionation and detection for metalloproteomics: challenges and approaches. Anal. Bioanal. Chem. 2012, 402, 3311-3322.

39. Casini, A.; Gabbiani, C.; Michelucci, E.; Pieraccini, G.; Moneti, G.; Dyson, P. J.; Messori, L., Exploring metallodrug-protein interactions by mass spectrometry: comparisons between platinum coordination complexes and an organometallic ruthenium compound $J$. Biol. Inorg. Chem. 2009, 14, 761-770.

40. Gibson, D., The mechanism of action of platinum anticancer drugs-what do we really know about it? Dalton Trans. 2009, 10681-10689.

41. Groessl, M.; Hartinger, C. G.; Polec-Pawlak, K.; Jarosz, M.; Keppler, B. K., Capillary electrophoresis hyphenated to inductively coupled plasma-mass spectrometry: a novel approach for the analysis of anticancer metallodrugs in human serum and plasma. Electrophoresis 2008, 29, 2224-2232.

42. Groessl, M.; Terenghi, M.; Casini, A.; Elviri, L.; Lobinski, R.; Dyson, P. J., Reactivity of anticancer metallodrugs with serum proteins: new insights from size exclusion chromatography-ICP-MS and ESI-MS. J. Anal. At. Spectrom. 2010, 25, 305-313.

43. Manley, S. A.; Byrns, S.; Lyon, A. W.; Brown, P.; Gailer, J., Simultaneous $\mathrm{Cu}$-, $\mathrm{Fe}$-, and $\mathrm{Zn}$-specific detection of metalloproteins contained in rabbit plasma by sizeexclusion chromatography-inductively coupled plasma atomic emission spectroscopy J. Biol. Inorg. Chem. 2009, 14, 61-74.

44. Sooriyaarachchi, M.; Morris, T. T.; Gailer, J., Advanced LC-analysis of human plasma for metallodrug metabolites. Drug Discov Today: Technol 2015, 16, e24-e30. 45. Slejkovec, Z.; Byrne, A. R.; Dermelj, M.,

Determination of organoarsenic compounds in urine and blood after seafood consumption and exposure to inorganic arsenic Acta Chim. Slov. 1994, 41, 83-85.

46. Francesconi, K. A.; Edmonds, J. S., Arsenic and marine organisms. Adv. Inorg. Chem. 1997, 44, 147-189. 47. Pei, K. L.; Gailer, J., Probing the interaction of arsenobetaine with blood plasma constituents in vitro: an SEC-ICP-AES study. Metallomics 2009, 1, 403-408.

48. Jahromi, E. Z.; White, W.; Wu, Q.; Yamdagni, R.; Gailer, J., Remarkable effect of mobile phase buffer on the $S E C$-ICP-AES derived $\mathrm{Cu}, \mathrm{Fe}$ and $\mathrm{Zn}$-metalloproteome 
pattern of rabbit blood plasma. Metallomics 2010, 2, 460468.

49. Manley, S. A.; Gailer, J., Analysis of the plasma metalloproteome by SEC-ICP-AES: bridging proteomics and metabolomics. Expert. Rev. Proteomics 2009, 6, 251-265.

50. Sarpong-Kumankomah, S.; Gailer, J., Identification of a haptoglobin-hemoglobin complex in human blood plasma. J. Inorg. Biochem. 2019, 201, 110802.

51. Rother, R. P.; Bell, L.; Hillmen, P.; Gladwin, M. T., The clinical sequelae of intravascular hemolysis and extracellular plasma hemoglobin. J. Am. Med. Assoc. 2005, 293, 1653-1662.

52. Sooriyaarachchi, M.; Gailer, J., Removal of Fe3+ and $\mathrm{Zn} 2+$ from plasma metalloproteins by iron chelation therapeutics depicted with SEC-ICP-AES. Dalton Trans. 2010, 39, 7466-7473.

53. Brook, C. E.; Harris, W. R.; Spilling, C. D.; Peng, W.; Harburn, J. J.; Srisung, S., Effect of ligand structure on the pathways for iron release from human serum transferrin. Inorg. Chem. 2005, 44, 5183-5191.

54. Kontoghiorghes, G. J.; Aldouri, M. A.; Sheppard, L.; Hoffbrand, A. V., 1,2-Dimethyl-3-hydroxypyrid-4-one, an orally effective chelator for treatment of iron overload. The Lancet 1987, 1294-1295.

55. Kontoghiorghes, G. J.; Agarwal, M. B.; Grady, R. $W$.; Kolnagou, A.; Marx, J. J., Deferiprone for thalassaemia. The Lancet 2000, 428-429.

56. Tuncel, S.; Dumoulin, F.; Gailer, J.; Sooriyaarachchi, M.; Atilla, D.; Durmus, M.; Bouchu, D.; Savoie, H.; Boyle, R. W.; Ahsen, V., A set of highly watersoluble tetraethyleneglycol-substituted Zn(II) phthalocyanines: synthesis, photochemical and photophysical properties, interaction with plasma proteins and in vitro phototoxicity. Dalton Trans. 2011, 40, 40674079.

57. Ferraro, G.; Massai, L.; Messori, L.; Merlino, A., Cisplatin binding to human serum albumin: a structural study. Chem. Comm. 2015, 51, 9435-9439.

58. $\quad$ Massai, L.; Pratesi, A.; Gailer, J.; Marzo, T.; Messori, L., The cisplatin/serum albumin systen: a reappraisal. Inorg. Chim. Acta 2019, 495, 118983.

59. Sherman, S. E.; Lippard, S. J., Structural aspects of platinum anticancer drug interactions with DNA. Chem. Rev. 1987, 87, 1153-1181.

60. Harper, B. W. J.; Morris, T. T.; Gailer, J.; AldrichWright, J. R., Probing the interaction of bisintercalating $\left(2,2^{\prime}: 6^{\prime} 2^{\prime \prime}\right)$ platinum(II) complexes with glutathione and rabbit plasma. J. Inorg. Biochem. 2016, 163, 95-102.

61. Eljack, N. D.; Ma, H.-Y. M.; Drucker, J.; Shen, C.; Hambley, T. W.; New, E. J.; Friedrich, T.; Clarke, R. J., Mechanism of cell uptake and toxicity of the anticancer drug cisplatin. Metallomics 2014, 6, 2126-2133.

62. Guo, W.; Zhang, W.; Luo, Q.; Li, X.; Zhao, Y.; Xiong, S.; Wang, F., Transferrin serves as a mediator to deliver organometallic ruthenium(II) anticancer complexes into cells. Inorg. Chem. 2013, 52, 5328-5338.

63. Wang, X.; Guo, Z., The role of sulfur in platinum anticancer chemotherapy. Anti-Cancer Agents Med. Chem. 2007, 7, 19-34.
64. Sooriyaarachchi, M.; Narendran, A.; Gailer, J., The effect of sodium thiosulfate on the metabolism of cis-platin in human plasma in vitro. Metallomics 2012, 4, 960-967.

65. Sooriyaarachchi, M.; Narendran, A.; White, W. H.; Gailer, J., Chemoprotection by D-methionine against cisplatin-induced side-effects: Insight from in vitro studies using human plasma Metallomics 2014, 6, 532-541.

66. Sooriyaarachchi, M.; Narendran, A.; Gailer, J., Nacetyl-L-cysteine modulates the metabolism of cis-platin in human plasma in vitro. Metallomics 2013, 5, 197-207.

67. Sooriyaarachchi, M.; Gibson, M. A.; Lima, B. d. S.; Gailer, J., Modulation of the metabolism of cis-platin in blood plasma by glutathione. Can. J. Chem. 2016, 94, 360366.

68. Sooriyaarachchi, M.; Gailer, J.; Dolgova, N. V.; Pickering, I. J.; George, G. N., Chemical basis for the detoxification of cisplatin-derived hydrolysis products by sodium thiosulfate. J. Inorg. Biochem. 2016, 162, 96-101. 69. Sooriyaarachchi, M.; George, G. N.; Pickering, I. J.; Narendran, A.; Gailer, J., Tuning the metabolism of the anticancer drug cisplatin with chemoprotective agents to improve its safety and efficacy Metallomics 2016, 8, 11701176.

70. Jedlitschky, G.; Leier, I.; Buchholz, U.; Barnouin, K.; Kurz, G.; Keppler, D., Transport of glutathione, glucuronate, and sulfate conjugates by the MRP geneencoded conjugate export pump. Cancer Res. 1996, 56, 988994.

71. Kondagunta, G. V.; Bacik, J.; Donadino, A.; Bajorin, D.; Marion, S.; Sheinfeld, J.; Bosl, G. J.; Motzer, R. $J$., Combination of paclitaxel, ifosfamide, and cisplatin is an effective second-line therapy for patients with relapsed testicular germ cell tumors. J. Clin. Oncol. 2005, 23, 65496555.

72. Khalaila, I.; Bergamo, A.; Bussy, F.; Sava, G.; Dyson, P. J., The role of cisplatin and NAMI-A plasmaprotein interactions in relation to combination therapy Intern. J. Oncol. 2006, 29, 261-268.

73. Kaiser, J., Combining targeted drugs to stop resistant tumors. Science 2011, 331, 1542-1545.

74. Sooriyaarachchi, M.; Wedding, J. L.; Harris, H. H.; Gailer, J., Simultaneous observation of the metabolism of cisplatin and NAMI-A in human plasma in vitro by SECICP-AES. J. Biol. Inorg. Chem. 2014, 19, 1049-1053.

75. Sarpong-Kumankomah, S.; Contel, M.; Gailer, J., SEC hyphenated to a multielement-specific detector unravels the degradation pathway of a bimetallic anticancer complex in human plasma. J. Chromatogr. B 2020, in press. https://doi.org/10.1016/j.jchromb.2020.122093

76. Gibson, M.A; Sarpong-Kumankomah, S.; Nehzati, S.; George; G.N.; Gailer, J. REmarkable differences in the biochemical fate of $\mathrm{Cd}^{2+}, \mathrm{Hg}^{2+}, \mathrm{CH}_{3} \mathrm{Hg}^{+}$and thimerosal in red blood cell lystae. Metallomics 2017, 9, 1060-1072.

77. Englinger, B.; Pirker, C; Heffeter, P.; Terenzi, A.; Kowol, C.R.; Keppler, B.K.; Berger W. Metal drugs and the anticancer immune response. Chem. Rev. 2019, 119, 15191624.

78. Massai, L.; Pratesi, A.; Gailer, J.; Marzo, T.;

Messori, L. The cisplatin/serum albumin system: a reappraisal. Inorg, Chim. Acta 2019, 495, 118983. 
79. Miodragovic, D.; Merlino, A.; Swindell, E.P.; Bogachov, A.; Ahn, R.W.; Abuhadba, S.; Ferraro, G.; Marzo, T.; Mazar, A.P.; Messori, L; O'Halloran, T.V. Arsenoplation-1 is a dual pharmacophore anticancer agent. J. Am. Chem. Soc. 2019, 141, 6453-6457.

80. Massai, L.; Cirri, D.; Michelucci, E.; Bartoli, G.; Guerri, A.; Cinellu, M.A.; Cocco, F.; Gabbiani, C.; Messori,
L. Organogold(III) compounds as experimental anticancer agents: chemical and biological profiles. Biometals 2016, 29, 863-872. 